Nonlin. Processes Geophys. Discuss., https://doi.org/10.5194/npg-2018-22

Manuscript under review for journal Nonlin. Processes Geophys.

Discussion started: 4 April 2018

(c) Author(s) 2018. CC BY 4.0 License.

\title{
Sampling strategies based on the Singular Value Decomposition for ocean analysis and forecast
}

\author{
Maria Fattorini ${ }^{1,2}$, Carlo Brandini ${ }^{1,2}$ \\ 50019, Italy \\ Correspondence to: Maria Fattorini (fattorini@lamma.rete.toscana.it)
}

${ }^{1}$ Istitute of Biometeorology (IBIMET,C.N.R.), via Madonna del Piano 10, Sesto Fiorentino, 50019, Italy

5 '2Laboratory of Environmental Monitoring and Modeling (LaMMA), via Madonna del Piano 10, Sesto Fiorentino,

Abstract. In this article we discuss some possible optimal sampling strategies for a simplified ocean model, used as a preliminary tool to understand the observation needs for real analysis and forecasting systems. Indeed, observations are mostly useful for improving the reliability of forecasting models, which require upstream an analysis model in which Data Assimilation techniques are used. In addition, observation networks and in particular in-situ networks are expensive and require careful positioning of a limited number of observation instruments. As in other literature studies, the Singular Value Decomposition has been adopted, which has many advantages, especially when we dispose of a variational assimilation method like the 4D-Var, also because the calculation of Singular Vectors and Singular Values is linked to the availability of tangent linear and adjoint models. SVD has been adopted here as a method for identifying areas where maximum error growth occurs, within which sampling gives particular advantages. However, a SVD-based sampling strategy may not be unique, and we need to introduce other criteria, based on the correlation between points, since the information observed on neighbouring points can be redundant. The criteria adopted are easily replicable in practical applications, and require rather standard studies to obtain prior information (for example, climatological and correlation studies), to be carried out in order to properly design observation networks.

\section{Introduction}

In recent years, there has been a growing demand for oceanographic forecast data (OECD 2016, She et al. 2016). Operational oceanographic services at basin scale but also, increasingly, at a regional scale, improve the reliability of their forecasts through data ingestion techniques applied to numerical prediction models. Observations play an essential role in these operational systems, as they allow to improve the estimate of the real ocean state through Data Assimilation (DA) and to evaluate the reliability of predictions. In the operational practice, a common procedure of initializing a simulation starting by external data (e.g. climatology, objective analysis, model analysis, etc.) requires a spin-up interval during which the solution is not useable: assimilation of suitable data can strongly reduce model errors and hopefully produce more reliable solutions. Although large amount of data comes from satellite observations, which have some intrinsic limitations (observable parameters, surface-limited observations, revisiting times), many parameters are only observable by collecting in-situ observations through specific sensor networks that integrate satellite observations with data along the water column and at higher frequencies. The main limit of such in-situ observation networks is their high cost for installation and maintenance over time, so it would be very important to design any observational network from the beginning on the basis of criteria that maximize the benefit of data, assuming a limited budget available for observations. 
Nonlin. Processes Geophys. Discuss., https://doi.org/10.5194/npg-2018-22

Manuscript under review for journal Nonlin. Processes Geophys.

Discussion started: 4 April 2018

(c) Author(s) 2018. CC BY 4.0 License.

This benefit can be measured, more appropriately, as an improvement in reliability both in the analysis and in the subsequent forecast. So a major problem is that to identify an observation network configuration that gives the largest advantage once data has been assimilated into the model. In particular, it is important that such criteria are objective and easily implementable in operational practice.

5 Many authors have dealt with the topic of measuring the impact of observations on assimilated forecasting systems, as the forecast reliability depends on the quality of analysis estimation (Ghil 1989) which in turns depends strongly on the particular assimilated dataset.

Whatever the DA scheme is used by modellers, assimilation process is normally able to limit the error growth of the state trajectory with respect to the real evolution (truth), provided that the quality and characteristics of observations are fo constraint the model to correct its evolution towards the real state.

Several theoretical and experimental studies, most of them referred to the atmospheric dynamics (e.g. Lorenz and Emanuel 1998, Berliner et al. 1999), have been conducted to choose an appropriate criterion of selection of observations mainly based on the perturbation theory. In fact, the source of divergence between the numerical model solution and the real state evolution is in the errors lied in model parameters (i.e. initial and boundary conditions,

15 forcing and numerical parameters). Such an approach to the problem therefore involves the assessment of the system stability and perturbations dynamics.

Since the well known fundamental milestone made by Lorenz in 1965, it is well known how the divergence in chaotic systems rises up from the unstable directions of the state trajectory where small errors strongly grow, leading over time to very different states. This puts a time limit to the predictability of the system state, which is usually evaluated by the largest Lyapunov exponents. The assimilation of observations attempts to prolong that time limit (Kantz et al., 2004). Some most significant errors could decay over time, while smaller errors could intensely grow and produce a heavy impact on the forecast reliability. The growth of the divergence between model evolution and the real state of the system is driven by these unstable directions, rather than by the largest components of the error lied in the elements of the predicting system (Toth and Kalnay 1993, Ehendorfer and Tribbia 1997). Hansen and Smith (2000) showed that for sufficiently small errors, sampling strategies based on dynamics produce better results than strategies based on error estimates. Indeed the structure of the fast growing perturbations, as well as the model uncertainty and the error of the day, is a dynamically evolving field and depends on the flow regime: it derives from the position of the current state on the attractor, and it varies over time (Lorenz 1965, Corazza et al. 2003, Palmer and Zanna 2013).

Estimation procedures of the more significant perturbations have been developed by many authors as the estimation of forecast errors is crucial not only in sampling strategies, but even in ensemble forecasts, for initializing all members. Both problems are faced by means of the same methods, to model the growing of errors in initial conditions.

For what concerns studies of ensemble predictions, procedures based on initializing the members by randomly perturbing the background state have been rejected because they underestimate the uncertainty dispersion (Palmer and Zanna, 2013) and there are a number of sources of uncertainty not controlled by the ensemble members (Buizza et a 1999). Transposing this concept to sampling strategies, we can expect that a suitable selection of observations, in number and position, on the basis of the analysis of perturbation growth, could improve the analysis and subsequent forecast more than a random sampling.

Some techniques for sampling are based on the breeding method developed in 1991 by Kalnay and Toth (Toth and Kalnay 1993, Lorenz and Emanuel 1998), and they were used both for initializing ensemble members and in sampling strategies (e.g. Bishop and Toth 1999, Szunyogh et al. 1999, Bishop et al. 2001). Breeding in the unstable subspace (Carrassi, et al. 2007) is also used to select observations. 
Nonlin. Processes Geophys. Discuss., https://doi.org/10.5194/npg-2018-22

Manuscript under review for journal Nonlin. Processes Geophys.

Discussion started: 4 April 2018

(c) Author(s) 2018. CC BY 4.0 License.

Another proposed approach is based on ensemble methods (Bishop et al. 2001, Majumdar et al. 2002, Houtekmar et al. 2005). Observing tools can be deployed inside a verification area to minimize the forecast error covariance, estimated by ensemble, with respect to a set of possible observation deployments (i.e. a set of observation operators) by computing how the ensemble members are transformed through DA (Buehner and Zadra 2006).

5 Finally, other approaches for sampling are based on linear methods as singular vectors or adjoint methods (e.g. Langland and Rohaly 1996, Palmer et al. 1998, Bergot et al. 1999, Buizza and Montani 1999, Pu and Kalnay 1999, Bergot et al. 2002).

In literature the behavior of perturbations in dynamical system was mainly addressed by stability analysis, in that instability is linked to the existence of exponentially growing normal modes in the linearized dynamical equations. In

10 models of oceanographic interest (Farrell and Joannou 1996, Moore et al. 2004) normal modes are not purely suitable to describe the perturbations dynamics in non-autonomous systems and for non-asymptotic time terms. In fact perturbations may grow even if all normal modes are stable and that is usually characterized by quickly growing transients and not by a gradual and continuous exponential growth, typical of normal modes (Moore et al. 2004). Also, the rate of error growth is much larger than normal modes and its spatial structure is more localized (Molteni and

15 Palmer, 1993). Nevertheless the number of unstable normal modes can indicate number and frequency of the observations necessary to stabilize it (Trevisan and Uboldi, 2004), and the number of the positive Lyapunov exponents in the system (Carrassi et al. 2007).

In their major work, Farrell and Joannou (1996) have reset mathematically the problem of system stability. They have extended the traditional modal stability theory, which furnishes asymptotic evaluation of normal operator, to the cases time depending systems, non-normal dynamic operators, and time transients.

This theory identifies the Singular Vectors (SV) as a suitable tool for the purpose of studying instabilities and perturbation growth in short-medium terms, namely temporal transients. The SV represent the orthogonal set of perturbations that maximally grow, obtained by linearizing the dynamics over a finite-time interval with respect to a specific norm (Diaconescu et al. 2012).

25 The existence of large singular values indicates that small errors in the initial background state can grow very rapidly, reducing the system predictability, and the respective singular vectors indicate the areas where disturbances grow faster. Analyses of SVs appear strategic to increase model predictability, by furnishing indication on where minimizing errors in initial conditions. Such analysis is made on the basis of the Singular Value Decomposition (SVD) of the linearized model in order to be able to control rapidly growing errors and consequently to increase forecast reliability (Gelaro et

30 al. 1998, Palmer et al. 1998, Buizza and Montani 1999). SVD can also be used to indicate additional measurements for a network (adaptive or targeting observations) or to select observations for DA or data thinning (e.g. Bauer et al. 2011). Uncertainties could be mostly connected to certain variables and to a limited area: having measures of these variables within that area could produce significant improvement in the state estimate, even larger than assimilating a higher number of measurements located elsewhere (randomly). Observation networks could be designed to catch, as frequently s needed, real data in specific areas characterized by strong perturbation growth.

The application of SVD criteria to select observations has been already applied in a number of studies, mostly related to operational aspects of atmospheric forecasting systems (Palmer et al. 1998, Buizza et al. 1999, Langland et al. 1999, Buizza et al. 2007, Cardinali et al. 2007). Bergot et al. (1999) individualizes the SVD as a useful tool to identify areas where sampling even few observations is able to significantly reduce forecast errors.

40 SVD was used for others different applications such as perturbing the initial state in ensemble forecasting to build the members (e.g. Molteni et al. 1993, Mureau et al. 1993, Buizza and Palmer 1995), exploring the predictability of some 
Nonlin. Processes Geophys. Discuss., https://doi.org/10.5194/npg-2018-22

Manuscript under review for journal Nonlin. Processes Geophys.

Discussion started: 4 April 2018

(c) Author(s) 2018. CC BY 4.0 License.

geophysical fluid processes as the ENSO (e.g. Blumenthal, 1991) or the Gulf Stream (e.g. Moore and Farrell, 1993), and understanding circulation variability (e.g. Fujii et al. 2008).

A review of experiments of sampling strategies can be read in Langland (2005) that confirms the utility of SVD information in selecting observations to be assimilated. The first experimental reference has been the so-called Fronts

5 and Atlantic Storm Track Experiment (FASTEX), which has given rise to an important portion of literature about the topic of adaptive observations (e.g. Gelaro et al 1999, Pu and Kalnay 1999). In these studies different targeting methods were applied for identifying the supplementary observations to be assimilated into atmospheric models. The analysis produced by removing the adaptive observations from the assimilated dataset was then compared to that obtained by removing random observations, and it was verified that the largest loss in term of model reliability was due to the lack of the observational components selected by SVD

Once the target area is identified, it is possible to identify the most efficient way to sample it, for instance which variables to measure, and/or which sampling frequency to use (homogenous or not, high or low frequency).

Based on this idea, two experiments were carried out by assimilating additional observations caught by aircraft in regions characterized by rapid growth SVs (Bishop and Toth 1999, Langland et al. 1999, Szunyogh et al. 1999): these experiments showed the SVs utility for ocean forecasting on seasonal time scales.

A forecasting system has to be set by taking into account different elements such as uncertainties in the initial conditions (Lorenz and Emanuel, 1998) and their evolution (Rabier et al. 1996), the DA scheme in use (Baker and Daley 2000, Bergot 2001, Doerenbecher and Bergot 2001, Bergot and Doerenbecher 2002), the characteristics of existing observation network (Morss et al. 2001) and the number of additional observing tools to be deployed.

Studies conducted by ECMWF (Buizza et al. 2007, Cardinali et al. 2007, Kelly et al. 2007) have demonstrated that the observation impact is strongly dependent on the used DA scheme. The question of predictability is strongly related to both observations and assimilation scheme used to synthesize initial conditions (Bergot, 2001).

As the forecast error depends on several elements (assimilation scheme, observations error, observations spatial distribution, model imperfection, ...) any sampling strategy should take into account of all these aspects. For a more significant improvement in forecasts, sampling should focus on the structure of the dominant SVs, in particular on the projection of the forecast/analysis errors on the first dominant SVs (Bergot et al. 1999). In some studies, based on a 3DVar variational DA scheme, it was shown that positioning observations exclusively on the extremes of the SVs is insufficient and that is necessary to have more observations within the identified area. This is possibly due to the particular DA scheme used that may not be able to produce flow-dependent structure (Buizza et al. 2007, Cardinali et al 2007, Kelly et al. 2007). Conversely, 4DVar scheme is expected to be more capable of propagating information from areas rich toward areas poor of observations, hence it is less vulnerable to data-gaps. Sampling strategies appear sensitive even to the particular region to which they are referred and to the season (Buizza et al. 2007, Bauer et al. 2011).

In this work, we are looking for operational criteria to establish an optimal sampling strategy of a simplified ocean system. By optimal sampling, we mean a strategy based on the use of a limited number of observations, assuming that these have a significant cost, in order to ensure the greatest possible benefit to an integrated assimilation/forecasting system. The benefit is measured with respect to short/medium range forecast (following analysis and forecast cycles of a few days), as required in the operational practice.

We have tested a strategy based on the SVD of the linearized dynamical operator whose validity requires sufficiently small error to ensure the model linearization around the background trajectory relevant respect to the dynamics of 
Nonlin. Processes Geophys. Discuss., https://doi.org/10.5194/npg-2018-22

Manuscript under review for journal Nonlin. Processes Geophys.

Discussion started: 4 April 2018

(c) Author(s) 2018. CC BY 4.0 License.

linearized system around the real system trajectory. At the same time we verify that any sampling strategy based on SVD may fail if it is not accompanied to other considerations linked to the flow structure. In this case we applied some simple criteria that combine a SVD analysis with a correlation analysis, that can be used to limit redundant observations.

5 The experiments have been carried out by using the ocean code ROMS (Haidvogel et al. 2008), which already includes suitable routines for the SVD computation implemented through the PARPACK library (Moore et al. 2004). We performed a set of numerical experiments assimilating different datasets and we investigated the effects on future forecasts. We work in a perfect model scenario hence errors lie just in the estimation of initial conditions.

In the section 2 the configuration of the experiment is presented: the description of the model, the DA scheme and the possible strategy for model sampling. Then we discussed the concept of SVD which is the fundamental idea that has been applied for setting the strategy to select observation position.

In section 3 the results of all experiments are reported; three selection strategies are proved, starting from a random localization strategy. A selecting procedure based on SVD and on a minimum fixed distance among observation points was also used, and results were also compared with those obtained imposing a maximum correlation among the variables of interest.

\section{Materials and Methods}

\subsection{The twin model experiment}

The reference model used is an idealized ocean model, widely known as Double-Gyre (DG). This model is conceptually much simpler than realistic simulations, nevertheless it is still relevant from an oceanographic point of view. In fact, the DG dynamics has been largely studied as a theoretical scheme of typical seasonal and inter-annual oscillations in the large-scale circulation observed in mid-latitude oceans. A better understanding of the variability in the DG circulation pattern is essential for the climate system predictability, as it is considered a powerful mechanism to transfer potential energy from equator towards the poles. DG is also an useful model to explore the formation of the western boundary currents in the North Pacific and the North Atlantic, as they are studied by observational data and numerical simulations (e.g. Haidvogel et al. 1992, Jaing et al. 1995, Speich et al. 1995)

The model domain is a large rectangular basin bounded by solid walls and it is forced by a constant wind stress, with a positive zonal component at its mid axis which is inverted to a negative zonal component towards the Northern and Southern boundaries. This particular wind distribution induces a couple of large interacting vortices both having a scale of about one thousand kilometers: a sub-polar anticyclonic gyre and a sub-tropical cyclonic gyre, whose stationary

30 depends on the eddy viscosity value set.

This configuration has been also reported by ROMS developers (Moore et al. 2004) to describe the functionalities of specific modeling tools such as the tangent linear model and the adjoint model of nonlinear code, as well as other tools like the SVD of the tangent linear propagator.

The spatial domain is a rectangular grid of size $1000 \mathrm{~km}$ in East-West direction and $2000 \mathrm{~km}$ in North-South direction.

The basin has a flat bathymetry 500 meters deep and all closed boundaries. The domain has been discretized horizontally in 56x110 cells and vertically in 4 s-levels equally spaced. The model is forced by a zonally uniform wind stress defined as a sinusoidal function of latitude:

$$
\tau_{x}=-\tau_{0} \cos \left(\frac{2 \pi y}{L_{y}}\right)
$$


Nonlin. Processes Geophys. Discuss., https://doi.org/10.5194/npg-2018-22

Manuscript under review for journal Nonlin. Processes Geophys.

Discussion started: 4 April 2018

(c) Author(s) 2018. CC BY 4.0 License.

where $\tau_{0}=0.05 \mathrm{Nm}^{-2}$ and $\mathrm{L}_{\mathrm{y}}$ is the meridional extent of the basin.

In our model configuration, ROMS code solves the 3D primitive equations in a beta-plane approximation centered at $45^{\circ} \mathrm{N}$ is. Density profiles are defined by an analytical stable profile of the active tracers as described in (Moore et al. 2004). The advection for both $3 \mathrm{D}$ momentum and tracers in the horizontal and vertical components is implemented by 5 respectively the third order upstream scheme along constant S-surfaces and the fourth order centered scheme. Horizontal turbulent processes are parametrized by a harmonic operator whose horizontal eddy viscosity and diffusivity is equal to $160 \mathrm{~m}^{2} / \mathrm{s}$. Although forced by a steady wind, such a model configuration is not stationary for this viscosity value, as circulation is characterized by an oscillating behavior with formation of smaller scale vortices and shifting of main current patterns. In fact, DG circulation shows a bifurcation (Shen et al., 1999), identified by a critical value of the Reynolds number: for values lower than it, the flow converges quickly to an unique steady state solution, which is structurally stable, while above that value, instabilities occur and the symmetry of the structure between sub-polar and sub-tropical cells is broken. The vertical turbulent mixing is parameterized by coefficients of vertical viscosity and diffusion of $1 \mathrm{~m}^{2} / \mathrm{s}$; a linear bottom friction is introduced with a coefficient of bottom drag of $8 \times 10^{-7} \mathrm{~m} / \mathrm{s}$.
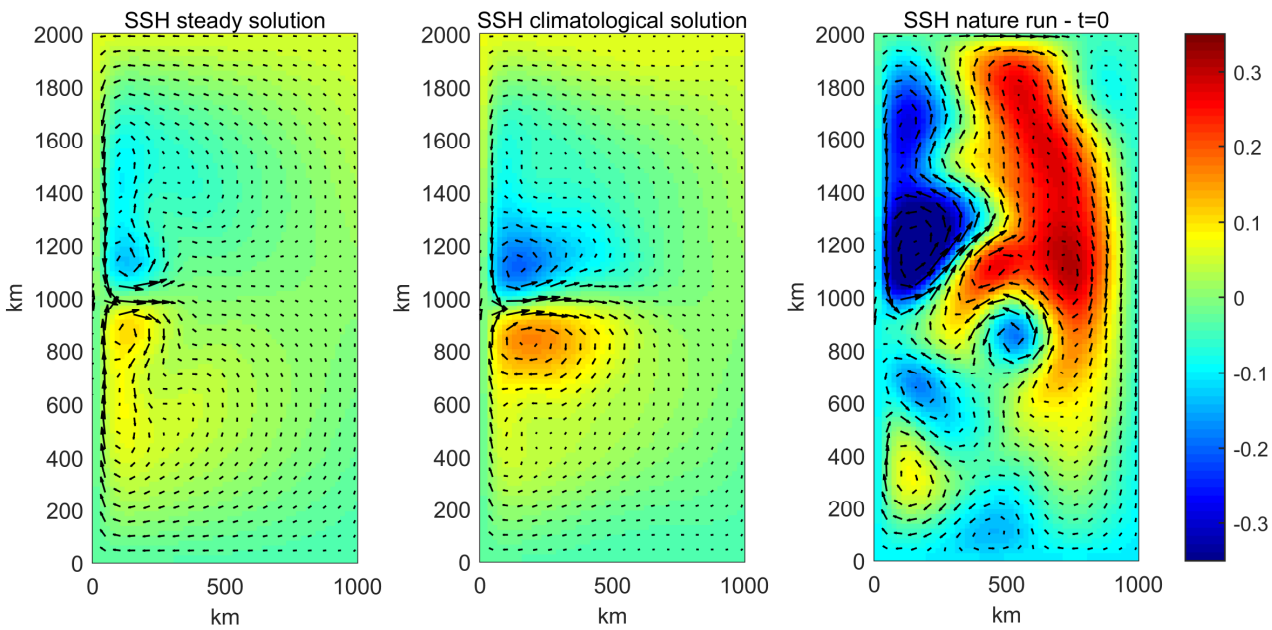

Figure 1. Current field (arrows) and Sea Surface Height (m) of (a) the steady solution, (b) the climatological state and (c) the initial state of the Nature Run for the first assimilation window.

The model was initially started through the steady solution (Fig. 1a), obtained by a 20 years long simulation with a high lateral friction, equals to $1280 \mathrm{~m}^{2} / \mathrm{s}$. Such steady circulation is characterized by a symmetric structure respect to the zonal axis and is composed of a Northern cyclonic gyre and a Southern anticyclonic gyre. Then, for the subsequent 10 years run, the lateral friction has been decreased to a more realistic value of $160 \mathrm{~m}^{2} / \mathrm{s}$ : in this case the circulation loses symmetry as it becomes an unsteady structure characterized by meandering where the two typical gyres move on all the domain and other gyres arise.

For our model experiments we define a couple of independent model run:

1) a Nature-Run (NR) that is the model initialized by the last snapshot of the last 10 years run (Fig. 1c); this has been run as the true state of the ocean, a virtual reality from which synthetic observations are extracted;

2) a Free-Run (FR) or background, that is the model initialized by an initial velocity field obtained by averaging the unsteady solution of the last 10 years run (Fig. 1b). This represents the common and simplest way to initialized numerical simulations by means of a "climatological" solution. 
Nonlin. Processes Geophys. Discuss., https://doi.org/10.5194/npg-2018-22

Manuscript under review for journal Nonlin. Processes Geophys.

Discussion started: 4 April 2018

(c) Author(s) 2018. CC BY 4.0 License.

In real cases, the design of observations network involves a methodology referred to as Observing System Simulation Experiment (OSSE), with the aim of assessing the impact of different choices of network configurations. In standard OSSE simulations, the synthetic observations are usually dirtied by some noise, to reproduce a more realistic behavior.

5 In our study we decided to treat synthetic data as perfect observations (no errors), as this avoids to add any further complexity to the problem.

Each experiment includes an analysis, produced by assimilating such particular errorless dataset over a window of 5 days, and the subsequent 5 days forecasts at the end of which the improvement is assessed by the comparison with the NR. The control vector corresponds just to the free-run (background) initial conditions since the reality has been

10 constructed by using the same model and parameters. Hence we assume that the model is able to reproduce all the processes of our virtual reality, as also forcing and boundary conditions are the same. The synthetic datasets consist of velocity observations, the number and positions of which are varied. Observations are extracted from the NR at a frequency of 15 minutes. The position of observations in the datasets has been chosen following three different strategies: 1) randomly, 2) in the area of maximum dominant singular vectors and imposing a minimum distance among

15 the positions, and finally 3 ) in the area of maximum dominant singular vectors and imposing a maximum limit of correlation between the velocity time series in each position. In order to reduce the dependence of the results on a particular spatial configuration of any dataset, characterized by the same number of measures, ensemble simulations based on all such different datasets were performed.

\subsection{Data assimilation scheme}

20 The assimilation of synthetic observations was executed through the incremental formulation of the 4DVar implemented in ROMS (ROMS-IS4DVar) and based on the Lanczos algorithm: it identified iteratively the incremental vector to correct the control vector which minimizes the cost function, as explained in (Moore et al. 2011). The minimum of the cost function, which corresponds to the maximum likelihood between model and data, is obtained by searching for the zero of the gradient of the cost function. The control vector is represented by the initial state vectors,

25 so just the initial conditions are adjusted by data.

In the code the background error covariance matrix $\mathrm{B}_{\mathrm{x}}$ is factorized by means of the univariate correlation matrix $\mathrm{C}$, the diagonal matrix of the prior error standard deviations $\Sigma x$, and the multivariate balance operator $K_{b}$, as described in (Moore et al 2011):

$$
B_{x}=K_{b} \Sigma_{x} C \Sigma_{x}^{T} K_{b}^{T}
$$

30 The background error standard deviations $\Sigma_{\mathrm{x}}$ was estimated by computing the climatological variance of the 10 years unsteady simulation. It is important to estimate it by running the model for a period long enough to compute meaningful circulation statistics.

The correlation matrix $\mathrm{C}$ is in turn factorized within the code through a diagonal matrix of grid box volumes $\mathrm{W}$, a horizontal and vertical correlation function model $\mathrm{L}_{\mathrm{h}}$ and $\mathrm{L}_{\mathrm{v}}$, and a matrix of normalization coefficients $\Lambda$, as:

$$
C=\Lambda L_{v}^{1 / 2} L_{h}^{1 / 2} W^{-1} L_{h}^{T / 2} L_{v}^{T / 2} \Lambda^{T}
$$

The normalization coefficients are used to ensure the diagonal elements of the associated correlation matrix $\mathrm{C}$ equal to unity. They have been computed by the so-called "exact method" within the code, imposing the horizontal and vertical isotropic decorrelation scales equals to $30 \mathrm{~km}$ and $100 \mathrm{~m}$. 
Nonlin. Processes Geophys. Discuss., https://doi.org/10.5194/npg-2018-22

Manuscript under review for journal Nonlin. Processes Geophys.

Discussion started: 4 April 2018

(c) Author(s) 2018. CC BY 4.0 License.

In the DA procedure, standard deviation of the background control vector was defined by using the standard deviation of the state variables fields during the 10 years unsteady simulation.

The DA procedure was carried out by imposing a maximum number of 10 inner cycles and 2 outer cycles. Independently on these maximum numbers of iterations, the assimilation process may stop as the minimization 5 procedure of the cost function gradient reaches the tolerance of $10^{-4}$.

\subsection{Singular Value Decomposition}

According to the Generalized Stability Theory (GST) of Farrell and Ioannou (1996), we resort to the Singular Value Decomposition (SVD) of the tangent propagator to identify the directions of maximum errors growth in a given time interval. In fact, the SVD is able, in the limit of linear approximation, to describe the time evolution of perturbations of ocean numerical models. Unlike normal modes, the singular vectors keep relevance in non-autonomous systems.

Following Kalnay (2003), we name $\mathrm{L}$ the tangent propagator: the $\mathrm{L}$ matrix is decomposed in three matrices such that $L V=U S$. The matrices $V$ and $U$ are formed by the eigenvectors respectively of $L^{T} L$ and $L L^{T}$ that are autonomous and symmetric for construction. Therefore their eigenvectors form two orthogonal basis respectively of the domain space and the range space. For this property, any disturbance at the initial time can be written as a linear combination of the initial singular vectors in the domain space, while its evolution can be written as a linear combination of the final singular vectors in the range space. Beside, the eigenvalues are the same for both matrices, $\mathrm{L}^{\mathrm{T}} \mathrm{L}$ and $\mathrm{LL}^{\mathrm{T}}$, and are called singular values; their square root corresponds to the growth factor of the relative initial singular vector, as they are transformed by $\mathrm{L}$. Therefore the growth rate of all the perturbations is confined by the faster growing singular mode, characterized the higher singular value. Its dominants initial singular vector defines the direction of maximum growth error in the interval $\left[\mathrm{t}_{1}, \mathrm{t}_{2}\right]$. This calculation allows to assess the fastest growing disturbance among all those possible during a certain finite time interval, called optimization time.

The SVD computation is controlled by two main parameters: the norm by which the growth of the singular vectors is valuated and the optimization time.

The dominant initial singular vector is calculated as the singular vector which maximizes a norm at the final time of the interval. Adopting different norms leads to different SVs. In oceanographic systems the norm commonly used is the total energy, although other norms have been used depending on the particular aim, as kinetic energy, enstrophy, and hessian norm (Palmer et al. 1998, Moore and Mariano 1999, Buehner and Zadra 2006, Moore et al. 2011, Smith at al. 2015).

The optimization interval should not be too long to avoid the nonlinear effects become important (the neglected $\mathrm{O}^{2}$ term), making the tangent linear model validity to fail. However, normally this assumption is legitimate and provides accurate results, at least for the perturbations which grow faster. This is essentially motivated by considering that commonly the perturbations, that grow on short time scales compared to the time scale of change of the state of a system, do not affect dramatically the perturbation development (Farrell, 1990).

In ROMS, through the Lanczos algorithm (Golub and van Loan 1989) the $n$ leading singular vectors are computed by first integrating the linear tangent model forward in time and thereafter by integrating the adjoint model backward in time a sufficient number of times for the convergence of the algorithm (Moore et al. 2004).

More details on the SVD can be found in Farrell and Ioannou (1996), which presents the GST, and in Moore et al. (2004) for the implementation of the SVD calculus in the ROMS code. 
Nonlin. Processes Geophys. Discuss., https://doi.org/10.5194/npg-2018-22

Manuscript under review for journal Nonlin. Processes Geophys.

Discussion started: 4 April 2018

(c) Author(s) 2018. CC BY 4.0 License.

The Singular Value Decomposition has been applied with respect to the tangent model of the free-run circulation starting from the climatological conditions. The system has a huge number of singular values of the order of $10^{5}$, anyway, just the 200 dominant singular vectors have been computed.

\section{Results}

5 As described in the previous sections, our experiment consists in sampling, through different possible strategies, an idealized ocean system (DG), then to assimilate such data in a twin model, and finally to identify which extracted dataset gives the maximum benefit both in the most correct identification of the final state, both in the subsequent forecast. A first possibility is to sample the system randomly, using a limited number of observation points.

Without any prior knowledge of the system dynamics, random sampling can be a strategy with which it is worthwhile to compare. We can also use it as a sort of benchmark for other possible sampling strategies that we will verify later, since any sampling based on more robust criteria should provide, on average, greater benefits than random sampling.

As first experiment, we tested the assimilation of an increasing number of surface velocity observations, randomly located. We started with 20 observation points and this test was repeated several times with different datasets. In fact, randomness can produce datasets more or less impactful for DA, hence in order to remove the impact of such chance factor, the test has been repeated considering different positions of observations, creating in this way an ensemble of analyses (Fig. 2).

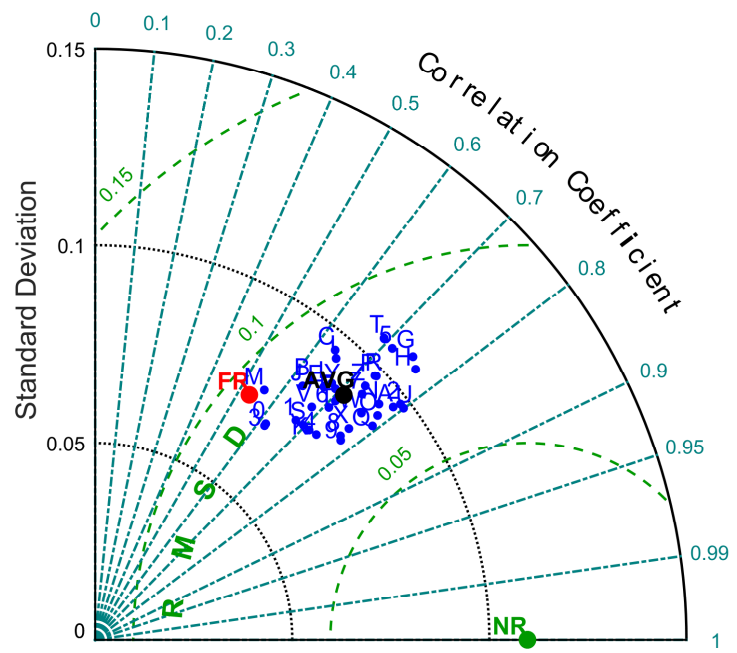

Figure 2. Representation in the Taylor diagram of the ensemble of the analyses obtained from datasets of velocity measures from 20 observation points randomly positioned (blue points), the Free Run (red point) and the Nature Run (green point), in 20 the first assimilation window.

Figure 2 shows, by mean of a Taylor diagram of the results, how analysis depends strictly by the position of observations, as it shows a wide spread between the analyses produced by assimilating different datasets corresponding to different networks having the same number of observing tools.

For our comparison we adopted the Taylor diagram representation (Taylor, 2001) as it includes in the same graph three of the most used statistical skills (mean root square error, correlation and standard deviation). We can see how some analyses, even characterized by high correlation, have low standard deviations with respect to the NR, and hence they poorly represent the true circulation structures. Statistical skills, such as the mean square error, are computed with 
Nonlin. Processes Geophys. Discuss., https://doi.org/10.5194/npg-2018-22

Manuscript under review for journal Nonlin. Processes Geophys.

Discussion started: 4 April 2018

(c) Author(s) 2018. CC BY 4.0 License.

respect to the whole surface velocity field. In particular, we reported the statistical skills related to the last time of the assimilation window, that we also take as initial condition for the forecast run.

In our Taylor diagrams representation, for a given time interval (in this case, for the initial assimilation window [0 5] days), two points are highlighted:

1) the Nature Run (NR), that we assume as the true state of the system;

2) the Free Run (RF), starting from climatological (fixed) initial conditions, that is poorly correlated with the NR (around 50\%).

We found an excellent capability of the DA algorithm (ROMS-IS4DVar) to adjust the initial condition and to bring the evolution of the state of the system close to the truth.

10 As expected, the reliability of analysis strongly depends on the particular dataset. Looking at the averaged statistics of analyses (named AVG in the graphs), even with a limited number of points, we have a positive effect of DA in improving the estimation of the model state. On the Taylor diagram we observe a significant spread of the results around such average (see Fig. 2), as analysis data can have a stronger (around 0.78), or a weaker correlation (around $0.64)$.

15 In Figure 3 we report the snapshots of the circulation of both the worst and the best analysis obtained, respectively, from the dataset $\mathrm{M}$ and the dataset $\mathrm{U}$; the observation points of these dataset on the circulation map of the NR are also reported.
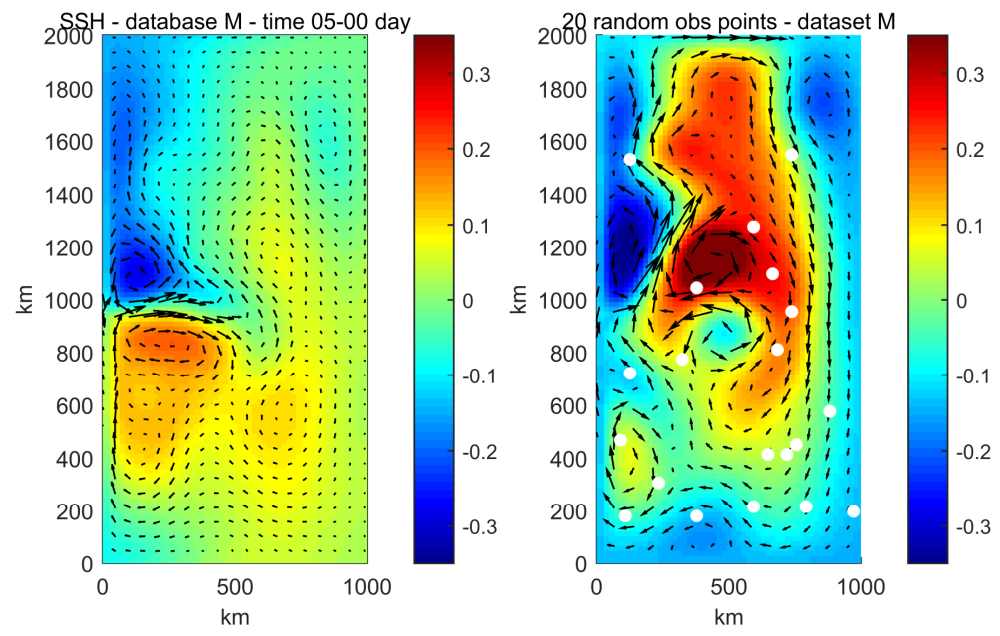
Nonlin. Processes Geophys. Discuss., https://doi.org/10.5194/npg-2018-22

Manuscript under review for journal Nonlin. Processes Geophys.

Discussion started: 4 April 2018

(c) Author(s) 2018. CC BY 4.0 License.
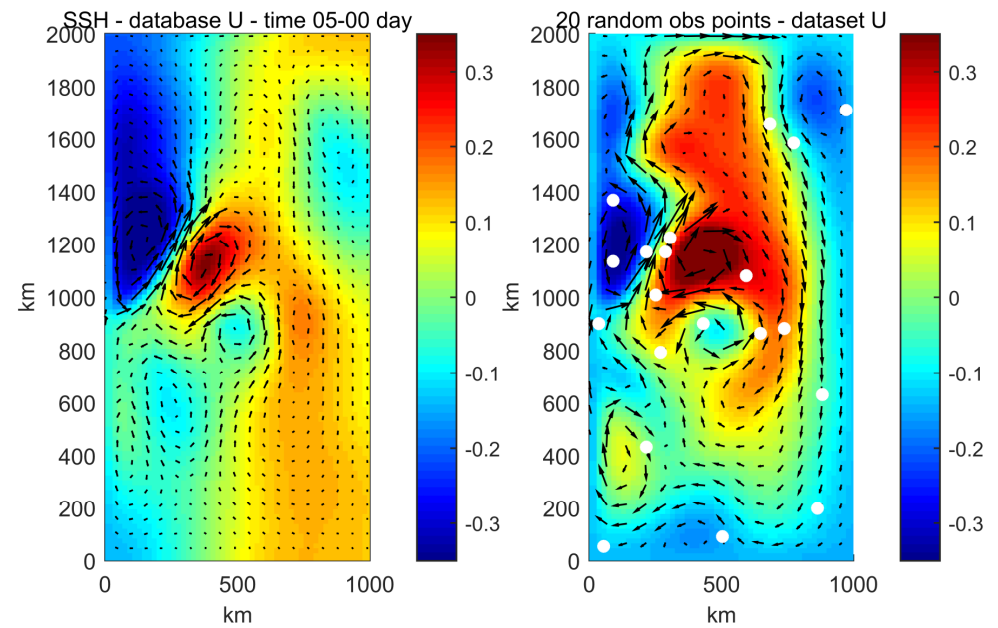

Figure 3. Snapshot of the sea surface height and velocity field of the analysis from the dataset $M$ (upper-left) and from the dataset $U$ (bottom-left) at the end of the assimilation window; (right) the observation points position forming the dataset $M$ (upper-right) and the dataset $\mathrm{U}$ (bottom-right) on the background of SSH and velocity field of the NR.

5

This first experiment was extended through the assimilation of ensembles of datasets characterized by a growing number of randomly positioned observation points $(40,60,80,100,150$ and 200).

Figure 4 shows how the assimilation of a higher number of observations produces analyses increasingly reliable, as expected. At the same time, in the Taylor diagram, the statistical skills associated to each member of each ensemble are more uniform, as we observe in the diagram, a more compact cloud of points as observation points increase. 
Nonlin. Processes Geophys. Discuss., https://doi.org/10.5194/npg-2018-22

Manuscript under review for journal Nonlin. Processes Geophys.

Discussion started: 4 April 2018

(c) Author(s) 2018. CC BY 4.0 License.

\section{(c) (1)}
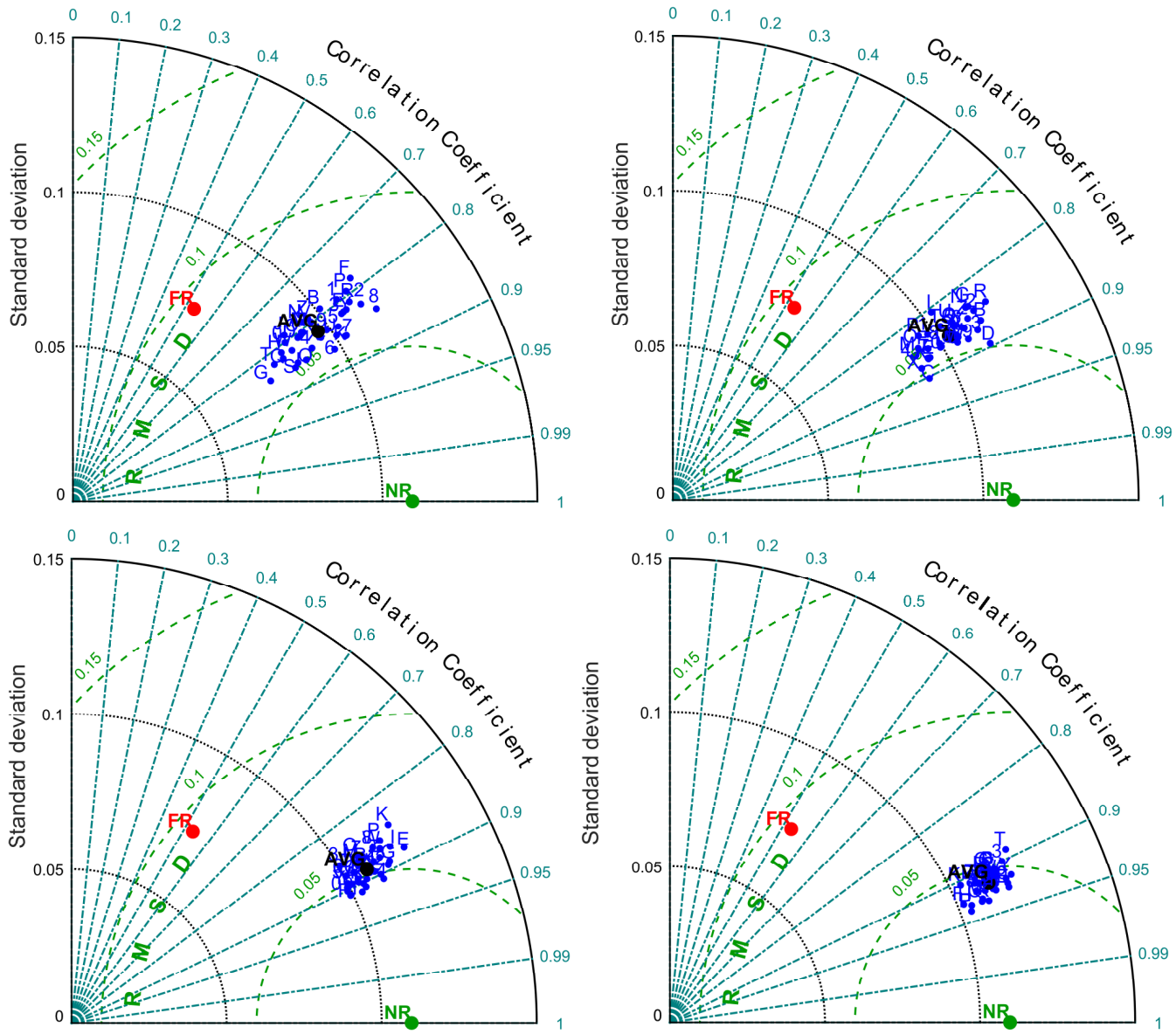

Figure 4. Representation in the Taylor diagram of the ensemble of the analyses obtained from datasets of velocity measures from, respectively, 40, 60, 80 and 150 observation points randomly positioned (blue points), Free Run (red point) and Nature 5 Run (green point), in the first assimilation window.

In Figure 5, the results of all tests with a same number of observation points are summarized by mean of a number of "average" points, each representing the averaged skills of the related ensemble. In the Taylor diagram we observe a progressively better quality of analyses, not only in terms of correlation and RMSE, but also with a standard deviation closer to the NR. At the same time, for increasing observation points, the marginal improvement of the analyses

decreases, and there is no much benefit in the assimilation of additional points. 
Nonlin. Processes Geophys. Discuss., https://doi.org/10.5194/npg-2018-22

Manuscript under review for journal Nonlin. Processes Geophys.

Discussion started: 4 April 2018

(c) Author(s) 2018. CC BY 4.0 License.
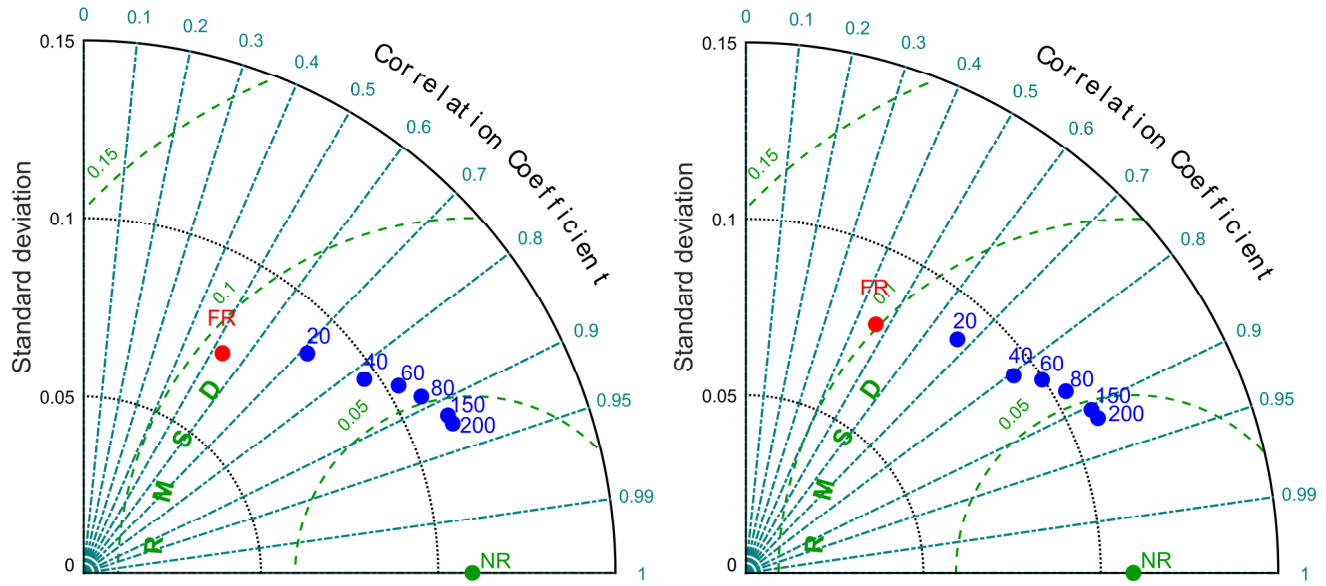

Figure 5. Representation in the Taylor diagram of the average point representing different ensemble of (a) the analyses obtained from datasets of velocity measures characterized by different number of observation points randomly positioned: $20,40,60,80,150$ and 200; (b) the subsequent forecast.
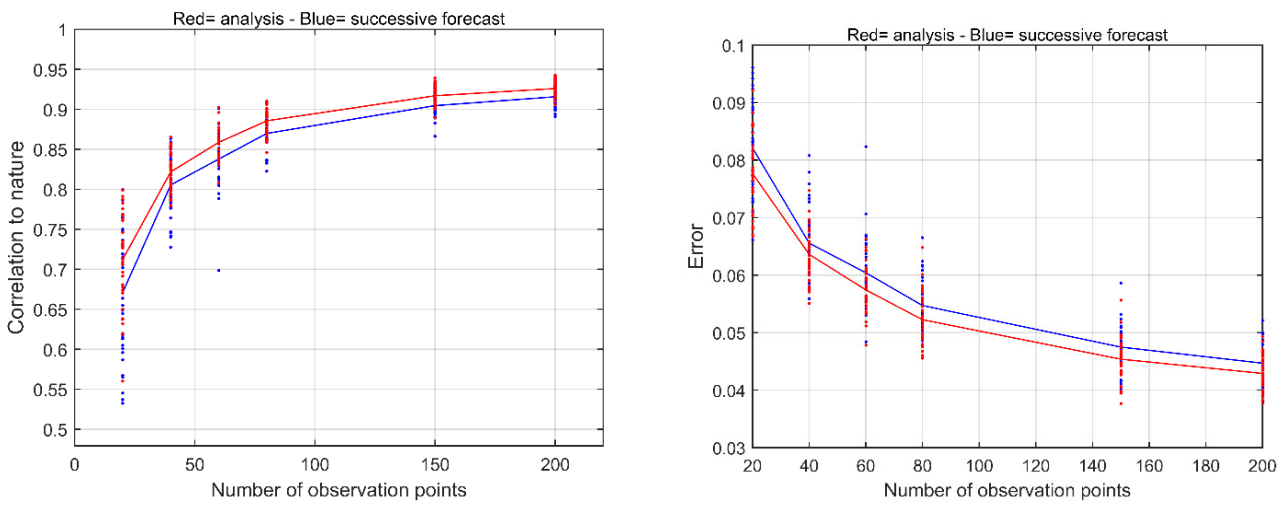

Figure 6. Correlation (left) and error (right) of the average point representing different ensemble (whose members are reported by single dots) of the analyses and the subsequent forecast obtained from datasets of velocity measures characterized by different number of observation points randomly positioned: 20, 40, 60, 80, 150 and 200.

This aspect is more visible in the correlation graph: in Figure 6 we reported both the improvement of the quality of

analysis as well as of the successive forecast for increasing number of observation points. As analyses are used to initialize the forecast runs, the red line, representing the initial state is always above the blue line (forecast). Nevertheless, as forecast reliability is strictly dependent on the quality of initial conditions, forecast skills show a relevant improvement for increasing observation points which is quite proportioned to the analysis reliability.

A further consideration on the effectiveness of random sampling leads us to consider that, just as the spread between the points of the Taylor diagram tends to decrease for increasing observation points (Fig. 6), a pure random strategy can only be suitable for large observation networks.

On the other hand, as the marginal increase of the analysis/forecast skills is more significative for a low number of assimilated observations, a suitable strategy to localize measuring tools is especially impactful in observations networks characterized by few instruments.

20 Looking at Figures 4 and 6, we note overlapped areas between the ensembles characterized by a significantly different number of observation points. This implies that datasets with a significant different number of observations can lead to 
Nonlin. Processes Geophys. Discuss., https://doi.org/10.5194/npg-2018-22

Manuscript under review for journal Nonlin. Processes Geophys.

Discussion started: 4 April 2018

(c) Author(s) 2018. CC BY 4.0 License.

a qualitatively equivalent analysis. The positions of observing tools can determine more or less advantageous data to improve DA results: a given number of instruments opportunely located can produce an analysis qualitatively equivalent to another produced by a larger network of instruments badly located. In fact, some datasets of the ensemble of well-positioned 20 observation points have produced results equivalent to some datasets of the ensemble of 40 or 5 even 60 observation points badly-positioned (Figs. 4 and 6).
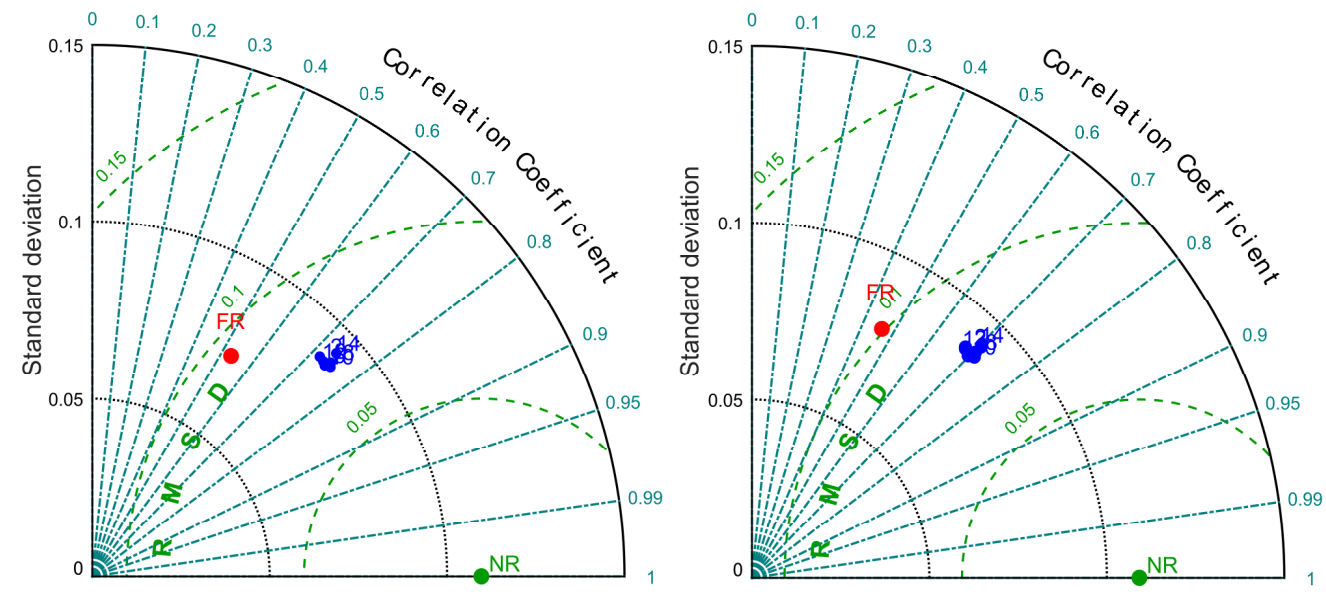

Figure 7. Representation on the Taylor diagram of the average points of several ensemble of the analyses obtained from datasets of velocity measures from 20 observation points randomly positioned under the only constrain to respect a minimum distance (from $0.02 * L_{R}$ to $0.036 * L_{R}$ ) among them (blue points), Free Run (red point) and Nature Run (green point), in the 10 first assimilation window.

The marginal improvement of the reliability of an ocean forecasting model can be obtained by a good selecting procedure able to identify advantageous positions for observing instruments. This can also be helpful to reduce the cost of extending an ocean observation network with additional tools.

Furthermore, the most advantageous positions for observations are not much controlled by the initial error map, instead they are related to the positions where the growing trend of errors is stronger (Hansen and Smith, 2000). In such positions, even a very small error can strongly increase because of inherent dynamics of the oceanographic model.

In our second set of experiments, we adopted a positioning strategy for observation points, which identifies locations characterized by higher values of the projection on the velocity components of dominant singular vectors. As dominant singular vectors have usually continuous structure and quite concentrated in specific areas (Fig. 8), a procedure only based on SVD would select observation positions too close to each others. The highest values of the SV component on the surface velocity are strictly localized in the middle of the western boundary where the ascending and descending currents converge. From one hand, it is crucial to control such area of maximum error growth with sufficient detail; from the other hand, having too many observation points concentrated in this part would not give a strong benefit since mean horizontal velocities are strongly correlated to each other. 
Nonlin. Processes Geophys. Discuss., https://doi.org/10.5194/npg-2018-22

Manuscript under review for journal Nonlin. Processes Geophys.

Discussion started: 4 April 2018

(c) Author(s) 2018. CC BY 4.0 License.
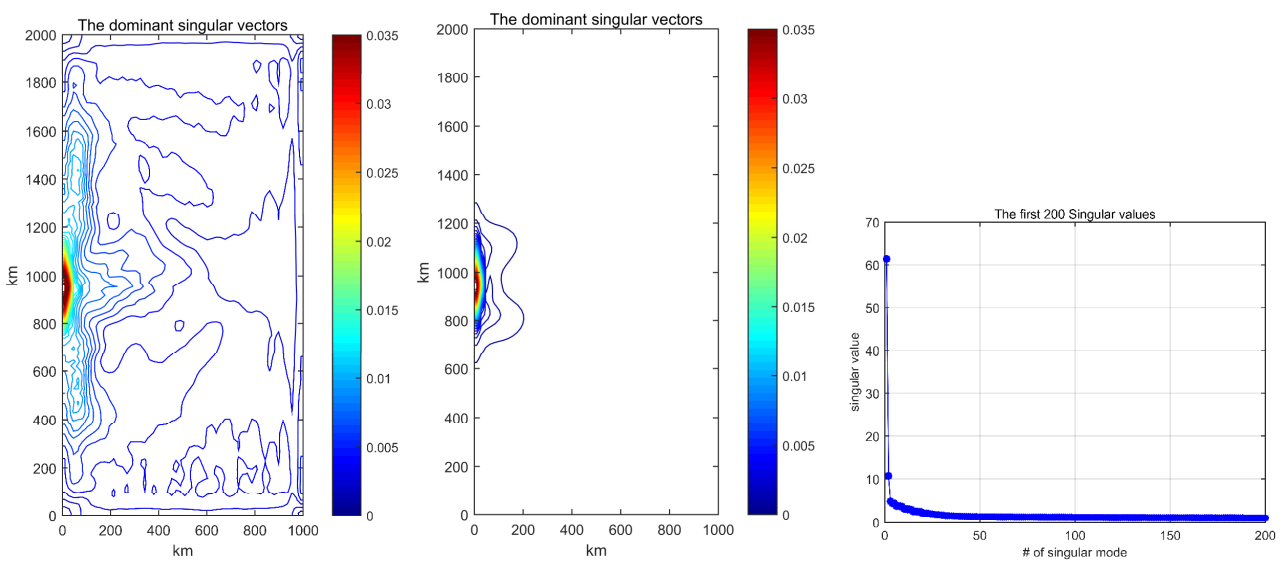

Figure 8. (left) Projection on the velocity component of the sum of the 200 dominant singular vectors, weighted on the relative singular values, computed in the Free Run; (central) projection of just the first singular vector; (right) the 200 singular values computed.

5 Too many observations in this convergence area contain a part of the same information. In some experiments, not reported in this paper, we found some inconsistent results when we tried to classify any single dataset of the first random experiments on the basis of the values of the dominant SV components on the observing points. Best skills were not associated to the highest value of the SV components for all such points. Moreover, some other experiments in which we sample our DG system by extracting measurements predominantly in this area, produced a dataset not so performant: the analysis of these data resulted even worse than many randomly positioned observations.

To be able to use a SVD-based method for the identification of sampling points, we need to introduce some criteria to avoid a selection of points too correlated to each others. As a first attempt, a minimum distance among observation points was added to the selecting procedure. Such set of experiments was carried out on the case of 20 observation points (Fig. 9) for assimilation window of 5 days.

15 To assess the selecting procedure for different hydrodynamic states, assimilation test was repeated in different time windows 30 days apart; in this way the strategies has been evaluated once a month, up to cover the span of a time period of a year. As previously stated, without any prior idea of the initial state of the system, we use the climatological solution obtained by averaging 10 years of the state of the system simulated by the NR. At time 0 , the state of NR that we assume as truth, is obviously quite far from this "averaged" state. With the same approximation, we can use the nitial climatological condition to simulate also different time windows (for example from day 30 to day $30+5$ ), in this case the only changing thing is the virtual reality to be chased, that is, the synthetic data extracted from the NR. Hence all analysis runs start by the same climatological initial conditions and they are forced by a constant wind distribution, but the solution of the NR that we assume as truth is different for each assimilation window. It is important to underline that the FR for all such simulations is the same, as well as the SVD, computed from this FR.

In this sampling strategy, the first point to select is where the velocity component of the dominant SV is maximum, the followings must also satisfy the requirement to be at a distance not less than the minimum distance with respect to the observations already selected. Hence, in each set of observation positions characterized by such minimum distance, only synthetic observed values are changed, as they are extracted by the NR.

The results of this second set of experiments are shown in Figures 9 and 11, in which we compare the correlations obtained by varying the minimum distance among points and for different assimilation windows. Distances are 
Nonlin. Processes Geophys. Discuss., https://doi.org/10.5194/npg-2018-22

Manuscript under review for journal Nonlin. Processes Geophys.

Discussion started: 4 April 2018

(c) Author(s) 2018. CC BY 4.0 License.

provided in dimensionless units, as they are divided by a typical length scale of geophysical interest, in this case we choose the barotropic Rossby deformation radius $L_{R}=(g h)^{1 / 2} / f \approx 900 \mathrm{~km}$.

Looking at the first assimilation window (0-5 days), the worse dataset corresponds to the imposed minimum distance of the order of the space discretization of the domain, that is $L_{R} / 20$; increasing this minimum distance we progressively 5 obtained better correlation up to a value approaching 0.8 for a minimum separation of about $0.25 * L_{R}$ (Fig. 9). The observation points positions of both the worst and the best dataset are reported in figure 12 on the snapshot of the nature circulation. Considering other assimilation windows, tested on data extracted on the same observation points, although results can be different, we reported some similar behavior, in that worst correlations are usually obtained for short minimum distances, then correlations tend to increase when we separate the observation points more, and most curves

10 have a maximum on the range $0.15-0.25 * L_{R}$ (Fig. 11).
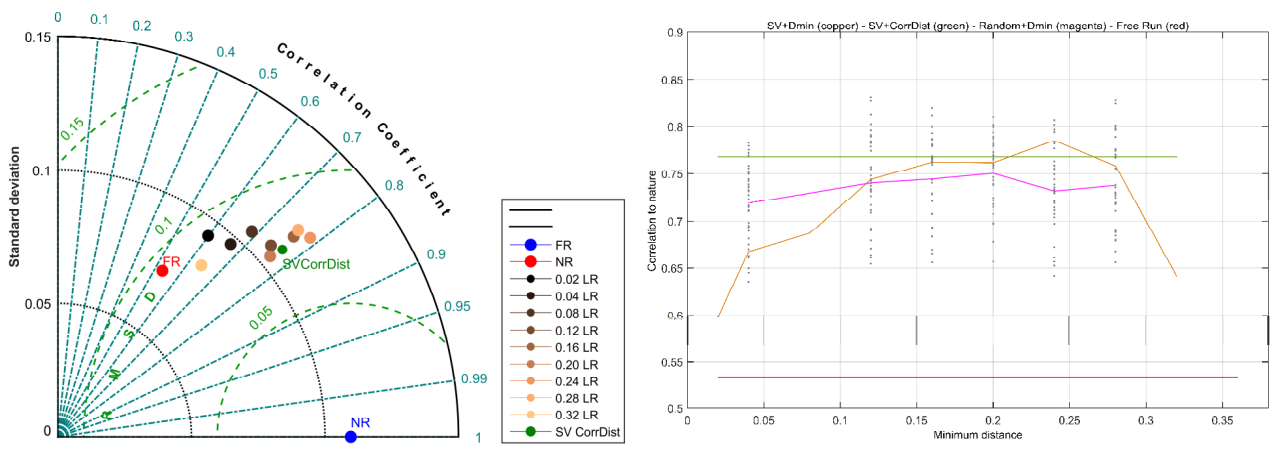

Figure 9. Representation in the Taylor diagram (left) and correlation graph (right) of the analyses obtained from datasets of velocity measures from 20 observation points positioned in high $\mathrm{SV}$ areas and by imposing a minimum distance among them which can be either a fixed value for whole domain (in the Taylor diagram, shaded copper points on the base of the fixed 15 distance imposed: lower values are associated to darker points; in correlation graph, grey dots) or a value defined for each grid cell reported in the correlation distance map of Fig. 10 (green point); the Free Run (blue point) and the Nature Run (green point), in the first assimilation window.

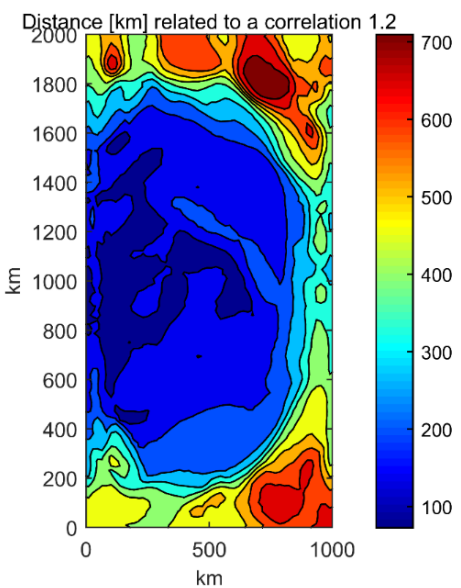

20 Figure 10. Map of the correlation distance $(\mathbf{k m})$ related to a correlation threshold of 1.2 among time series of both components of velocity in each grid cell of discretized domain. 
Nonlin. Processes Geophys. Discuss., https://doi.org/10.5194/npg-2018-22

Manuscript under review for journal Nonlin. Processes Geophys.

Discussion started: 4 April 2018

(c) Author(s) 2018. CC BY 4.0 License.

Taking the average of all curves referred to the whole set of assimilation windows, we see that on average best correlations are obtained by imposing a minimum distance of about $0.2 * \mathrm{~L}_{\mathrm{R}}$ (Fig. 11).

Looking at Figure 11, we note that our analyses based on this selection procedure, in terms of standard deviation, are always better, on average, than that based on random positioning; hence, using the SVD to identify the positions of 5 measurements produced, in any case, more detailed circulation patterns.

With respect to randomly selected observations, datasets selected by imposing a distance until $0.08-0.1 * \mathrm{~L}_{\mathrm{R}}$, produced worse analysis; the same happen when we set minimum distances too long, bigger than $0.3 * \mathrm{~L}_{\mathrm{R}}$. In the range between $0.1 * L_{R}$ to $0.25-0.3 * L_{R}$ this selecting procedure produces, on average, state estimates more reliable than that corresponding to random positioning.
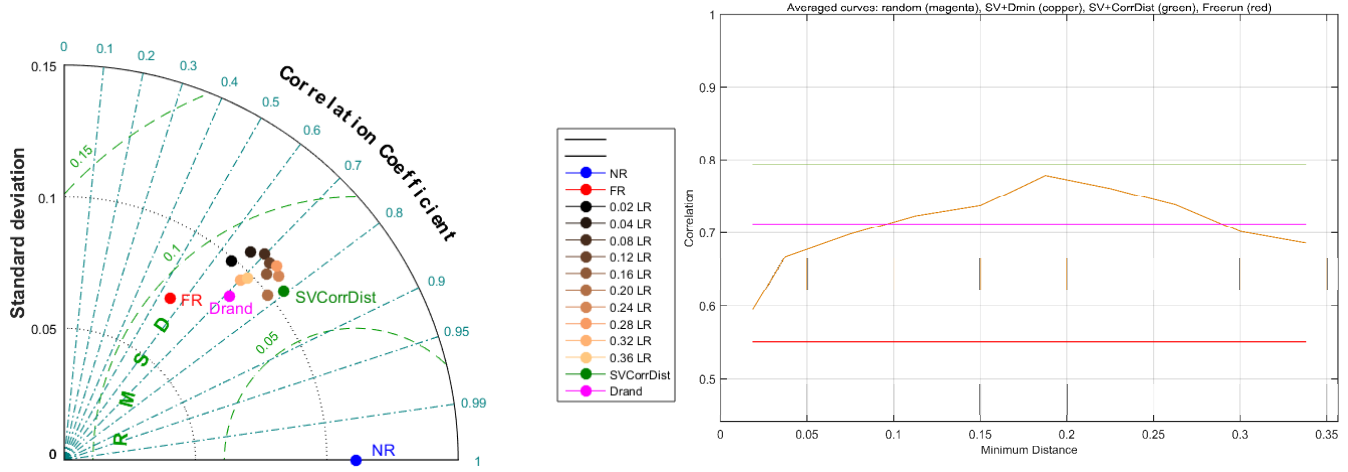

Figure 11. Representation in the Taylor diagram (left) and correlation graph (right) of the average of the analyses ensemble, for the all assimilation windows, obtained from datasets of velocity measures from 20 observation points positioned in high SV areas and by imposing a minimum distance among them which can be either a fixed value for whole domain (in the Taylor diagram, the shaded copper points on the base of the fixed distance imposed: lower values are associated to darker 15 points; in correlation graph, the blue line) or a value defined for each grid cell reported in the correlation distance map of Fig. 10 (green point); the Free Run (blue point) and the Nature Run (green point).

The analyses obtained for different assimilation windows are characterized by different correlations with the NR whose dynamical evolution is different in each considered time periods, while the background model is exactly the same. This explains why some performances are apparently less significative, i.e. the sharp green curve of Figure 13, in this case

20 the correlation between FR and NR is low, around 0.3, while in other assimilation windows we start from higher correlations.

It should be stressed that the imposition of a minimum distance in the absence of other criteria, is not sufficient to produce significant improvements. Indeed, adopting only the criterion of the minimum distance but with random positioning, the results of assimilation appear to be less performing (Fig. 7).

25 This selection criteria based on the SVD and imposing a fixed minimum distance between the observation points, takes into account only empirically that it is advisable to avoid sampling points too close to each other and therefore correlated. Moreover we expect that in most hydrodynamic field of interest the correlation can not be homogeneous in all points. As third set of experiments we tested a procedure, still based on SVD, where we imposed a maximum correlation between the time series of observations at the sampling positions, instead of a fixed minimum distance.

30 Therefore, these selected locations are characterized by both a relative high value of the dominant SV and simultaneously by a correlation lower than a given value.

The limitation of the correlation between the time series of velocities recorded at observation points has been introduced by imposing a minimum distance computed as following: 
Nonlin. Processes Geophys. Discuss., https://doi.org/10.5194/npg-2018-22

Manuscript under review for journal Nonlin. Processes Geophys.

Discussion started: 4 April 2018

(c) Author(s) 2018. CC BY 4.0 License.

1) To identify that distance it has been computed all the correlations for each grid cell between its velocity components time series and that of all the other grid cells. With respect to a generic grid cell $(i, j)$, the velocity correlation with all other grid points $(h, l)$ can be computed as:

$$
\left|\begin{array}{ll}
<u_{i j} u_{h l}> & <v_{i j} u_{h l}> \\
<u_{i j} v_{h l}> & <v_{i j} v_{h l}>
\end{array}\right|
$$

5 in this way we take into account even of possible correlation between u (zonal) and v (meridional) components, for instance in proximity of the flow convergence area of the DG and near closed boundaries. Each cell can be associated to a single map of correlation, by computing for all grid points the standard norm of the correlation matrix, whose value falls within the range from 0 (uncorrelated grid cells) to 2 (perfectly correlated grid cells).

2) Imposing a maximum value for such norm, we calculate a distance beyond which the correlation is averagely lower than a prefixed threshold. In such a way all correlation maps for each grid cell can be transformed into a single map of distances. This map of minimum distance among observation points is computed as the medium radius inside which the correlation of the variable to be measured is over an imposed maximum correlation.

Figure 10 shows the map of distances computed by imposing a maximum correlation of the time series of velocities equal to 1.2: in each grid cell this map shows the minimum distance necessary for selecting a new observation point characterized by a norm of the correlation matrix less than 1.2. The selecting procedure for the third set of experiments is based on this map: given a point chosen as observation location, for example where we computed the maximum value of the SV, through this map we identify the minimum distance suitable for placing an additional observation point.
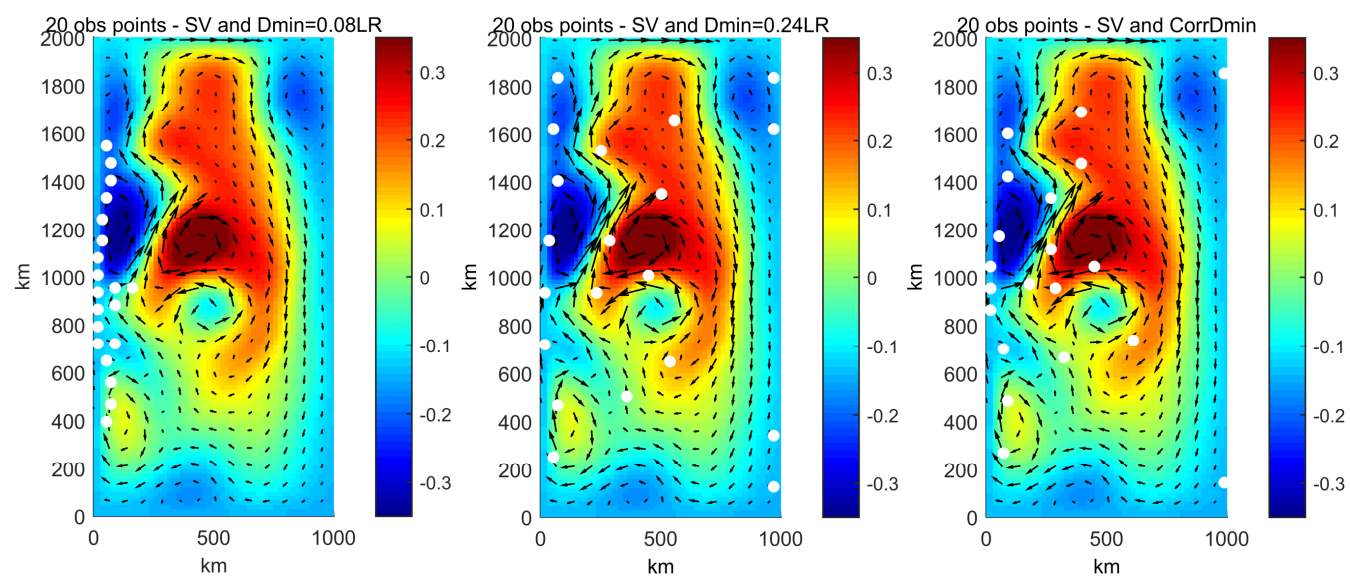

Figure 12. Observation points of dataset selected by the procedure based on SVD and imposing a distance limit of $0.08 L_{R}$ 20 (upper left), imposing a minimum distance of $0.24 * \mathbf{L}_{R}$ (upper right), and produced by the procedure based on SVD and the correlation distance map of Fig. 10 in the first assimilation window. 
Nonlin. Processes Geophys. Discuss., https://doi.org/10.5194/npg-2018-22

Manuscript under review for journal Nonlin. Processes Geophys.

Discussion started: 4 April 2018

(c) Author(s) 2018. CC BY 4.0 License.

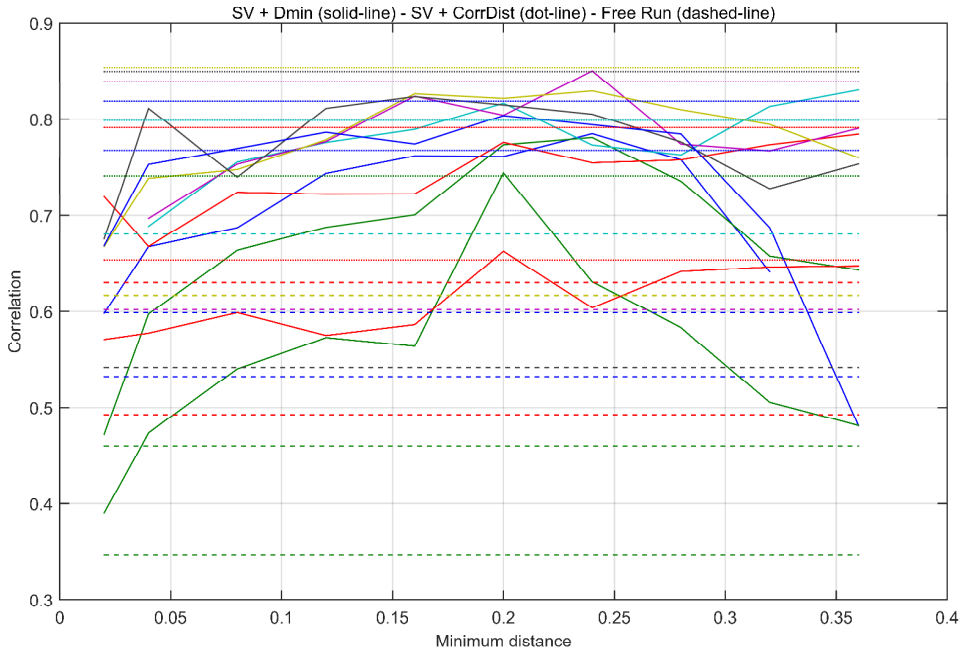

Figure 13. Correlation graph of the analyses obtained from datasets of velocity measures from 20 observation points positioned in high SV areas and by imposing a minimum distance among them which can be either a fixed value for whole domain (broken lines) and a value defined for each grid cell e reported in the correlation distance map of Fig. 10 (horizontal lines); Free Run (dashed horizontal lines) in all the 10 assimilation window.
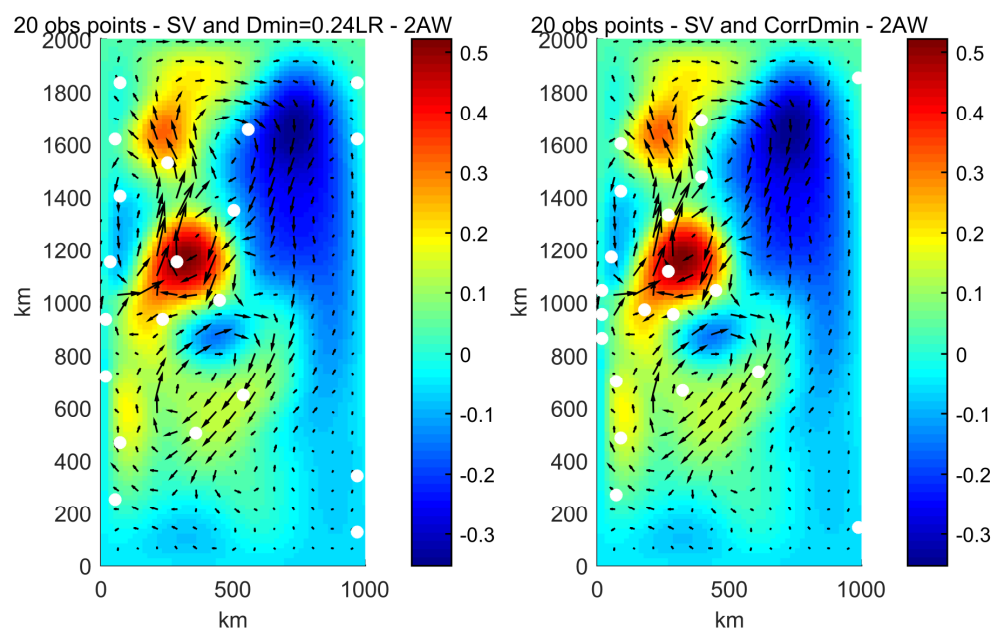

Figure 14. Observation points of dataset selected by the procedure based on SVD and distance limit of $0.24 * L_{R}$ and of dataset selected by the procedure based on SVD and the correlation distance map of Fig. 10, in the second assimilation window.

It is important to underline that this positioning strategy is univocal, once the correlation threshold has been defined.

This threshold should be itself a calibration parameter, to be identified on the basis of the correlation value that may guarantee the best comparison between model and observations. Anyway, calculating the average value of this correlation distance on the map, we found a value around $300 \mathrm{~km}$, that is around $0.3 * \mathrm{~L}_{\mathrm{R}}$, that is slightly outside the "best" minimum distance found for the second set of experiments with fixed separation among observations. However, this distance, in the map, varies between lower values (around 150-200 km) near the convergence area, while higher values $(>600 \mathrm{~km})$ are found near the northern and southern edges. The highest SVs are located within the area of lower 
Nonlin. Processes Geophys. Discuss., https://doi.org/10.5194/npg-2018-22

Manuscript under review for journal Nonlin. Processes Geophys.

Discussion started: 4 April 2018

(c) Author(s) 2018. CC BY 4.0 License.

correlation distances that fall within the range $0.15-0.20 \mathrm{~L}_{\mathrm{R}}$ that we had found, empirically, as an optimal distance interval using the rigid distance criterion.

We have assimilated into the DG model the datasets selected by such procedure based on SVD and the correlation distance map, in the same assimilation windows considered in the second set of experiments.

5 The procedure is able, on average, to improve the reliability of the analysis model both with respect to the random procedure, and with respect to the previous procedure based on a fixed distance. (Figs. 11 and 13). Figures 12 and 14 report the positioning for some datasets composed by different strategies used for the first and the second assimilation windows.

Although the parameter corresponding to the correlation threshold has not yet been calibrated, the univocal dislocation of the observation points determined by the last sampling strategy is that which gives, on average, the best results.

\section{Discussion and conclusions}

The Singular Value Decomposition has been already used by various authors in the fields of Geophysical Fluid Dynamics (mainly in atmosphere) to identify possible adaptive sampling strategies. However, the analysis of the potential of this method is still rather lacking to provide effective and functional indications for the design of in-situ

15 observation networks.

In this work, an attempt was made to define a strategy based on SVD to determine an optimal set of sampling points in the case in which only a limited number of observation points are available. This case is common in reality, given the high cost of installing and managing in-situ observation networks, especially in the oceanographic field.

Many ensemble-type simulations were carried out, with repeated analysis and forecast cycles, using a variational 20 assimilation scheme known as ROMS-IS4DVar.

We first proceeded to evaluate the benefit linked to the assimilation of randomly positioned observations. The assimilation method in use always produces a positive improvement in the estimation of the state of the system. The effectiveness of this improvement is not uniform, but it depends quite complexly on the number of observation points, and also on the location of these points in the model domain. This is especially evident for a limited number of points.

25 Having a limited number of observation points available, and looking for the positions that give maximum benefit to DA, we assume that a fundamental indication for sampling can be provided from the study of the areas where the maximum error growth occurs. From this point of view it is believed that SVD is an excellent method and the identification of the dominant SV, and in particular of its projection on the physical components of interest, can give important information about error dynamics, in the limit of validity of the tangent linear model. However, information obtained from points too close to each other is likely to be too correlated (i.e. redundant). To avoid this effect, two practical, easily replicable criteria have been used:

- a first criterion, based on a rigid distance, has identified an optimal separation distance equal to about one fifth of the Barotropic Rossby Deformation Radius; around this value we have, on average, the best skills for the analysis model compared to the NR.

- a second criterion, based on the maximum correlation, adopts a varying minimum distance among observation points; this criterion, defined univocally (but on the basis of a correlation threshold to be calibrated) provides better results both with respect to random simulations and with respect to the previous optimization criterion. 
Nonlin. Processes Geophys. Discuss., https://doi.org/10.5194/npg-2018-22

Manuscript under review for journal Nonlin. Processes Geophys.

Discussion started: 4 April 2018

(c) Author(s) 2018. CC BY 4.0 License.

It is important to note that further improvements of the last criterion can be achieved through an accurate calibration of the threshold parameter. However, even adopting a threshold parameter of first attempt, obtained results are, on average, better than any previously adopted strategy.

Obviously, the extension of these concepts in other applications is not straightforward, i.e. in the case of realistic 5 models and using not perfect observations, as in this case, but affected by measurement errors.

In the case of ocean models more complex than the DG, as the dynamics related to density variations are very important, the evaluation of the projection of the dominant SV on other variables, such as temperature and salinity, is also very important and any sampling strategy cannot disregard the acquisition of density profiles.

In the case of realistic applications, it will be interesting to test such criteria to the design of observation networks, as in the OSSEs used for simulating the benefits of observing systems. Such methods normally are not based on the study of the dynamic properties of the system, as in this case. In fact, most existing ocean observation networks have not been very often designed from the very beginning using objective criteria to optimally support analysis/forecast models. Suitable designing strategies are hence needed, for both designing new observational systems and expanding the existing ones in order to improve their efficiency.

\section{References}

Baker, N. L. and Daley, R.: Observation and background adjoint sensitivity in the adaptive observation-targeting problem. Quarterly Journal of the Royal Meteorological Society, 126(565), 1431-1454, 2000.

Bauer, P., Buizza, R., Cardinali, C., and Noël Thépaut, J.: Impact of singular-vector-based satellite data thinning on NWP. Quarterly Journal of the Royal Meteorological Society, 137(655), 286-302, 2011.

20 Bergot, T., Hello, G., Joly, A., and Malardel, S.: Adaptive observations: A feasibility study. Monthly weather review, 127(5), 743-765, 1999.

Bergot, T.: Influence of the assimilation scheme on the efficiency of adaptive observations. Quarterly Journal of the Royal Meteorological Society, 127(572), 635-660, 2001.

Bergot, T. and Doerenbecher, A.: A study on the optimization of the deployment of targeted observations using adjointbased methods. Quarterly Journal of the Royal Meteorological Society, 128(583), 1689-1712, 2002.

Berliner, L. M., Lu, Z. Q., and Snyder, C.: Statistical design for adaptive weather observations. Journal of the Atmospheric Sciences, 56(15), 2536-2552, 1999.

Bishop, C. H. and Toth, Z.: Ensemble transformation and adaptive observations. Journal of the atmospheric sciences, 56(11), 1748-1765, 1999.

30 Bishop, C. H., Etherton, B. J., and Majumdar, S. J.: Adaptive sampling with the ensemble transform Kalman filter. Part I: Theoretical aspects. Monthly weather review, 129(3), 420-436, 2001.

Blumenthal, M. B.: Predictability of a coupled ocean-atmosphere model. Journal of climate, 4(8), 766-784, 1991.

Buehner, M. and Zadra, A.: Impact of flow-dependent analysis-error covariance norms on extratropical singular vectors. Quarterly Journal of the Royal Meteorological Society, 132(615), 625-646, 2006.

35 Buizza, R. and Palmer, T. N.: The singular-vector structure of the atmospheric global circulation. Journal of the Atmospheric Sciences, 52(9), 1434-1456, 1995.

Buizza, R., Milleer, M., and Palmer, T. N.: Stochastic representation of model uncertainties in the ECMWF ensemble prediction system. Quarterly Journal of the Royal Meteorological Society, 125(560), 2887-2908, 1999. 
Nonlin. Processes Geophys. Discuss., https://doi.org/10.5194/npg-2018-22

Manuscript under review for journal Nonlin. Processes Geophys.

Discussion started: 4 April 2018

(c) Author(s) 2018. CC BY 4.0 License.

Buizza, R. and Montani, A.: Targeting observations using singular vectors. Journal of the Atmospheric Sciences, 56(17), 2965-2985, 1999.

Buizza, R., Cardinali, C., Kelly, G., and Thépaut, J. N.: The value of observations. II: The value of observations located in singular-vector-based target areas. Quarterly Journal of the Royal Meteorological Society, 133(628), 1817-1832,

52007.

Cardinali, C., Buizza, R., Kelly, G., Shapiro, M., and Thépaut, J. N. (2007). The value of observations. III: Influence of weather regimes on targeting. Quarterly Journal of the Royal Meteorological Society, 133(628), 1833-1842, 2007.

Carrassi, A., Trevisan, A., and Uboldi, F. Adaptive observations and assimilation in the unstable subspace by breeding on the data-assimilation system. Tellus A, 59(1), 101-113, 2007.

10 Corazza, M., Kalnay, E., Patil, D. J., Yang, S. C., Morss, R., Cai, M., ... and Yorke, J. A.: Use of the breeding technique to estimate the structure of the analysis" errors of the day". Nonlinear Processes in Geophysics, 10(3), 233-243, 2003.

Diaconescu, E. P. and Laprise, R.: Singular vectors in atmospheric sciences: A review. Earth-science reviews, 113(3-4), 161-175, 2012.

Doerenbecher, A. and Bergot, T.: Sensitivity to observations applied to FASTEX cases. Nonlinear processes in 15 geophysics, 8(6), 467-481, 2001.

Ehrendorfer, M. and Tribbia, J. J.: Optimal prediction of forecast error covariances through singular vectors. Journal of the Atmospheric Sciences, 54(2), 286-313, 1997.

Farrell, B. F.: Small error dynamics and the predictability of atmospheric flows. Journal of the Atmospheric Sciences 47.20 (): 2409-2416, 1990

20 Farrell, B. F. and Ioannou, P. J.: Generalized stability theory. Part I: Autonomous operators. Journal of the atmospheric sciences, 53(14), 2025-2040, 1996.

Farrell, B. F. and Ioannou, P. J.: Generalized stability theory. Part II: Nonautonomous operators. Journal of the Atmospheric Sciences, 53(14), 2041-2053, 1996.

Fujii, Y., Tsujino, H., Usui, N., Nakano, H., \& Kamachi, M.: Application of singular vector analysis to the Kuroshio 25 large meander. Journal of Geophysical Research: Oceans 113.C7, 2008.

Gelaro, R., Buizza, R., Palmer, T. N., and Klinker, E.: Sensitivity analysis of forecast errors and the construction of optimal perturbations using singular vectors. Journal of the atmospheric sciences, 55(6), 1012-1037, 1998.

Gelaro, R., Langland, R. H., Rohaly, G. D., and Rosmond, T. E.: As assessment of the singular-vector approach to targeted observing using the FASTEX dataset. Quarterly Journal of the Royal Meteorological Society, 125(561), 3299-

$303327,1999$.

Ghil, M.: Meteorological data assimilation for oceanographers. Part I: Description and theoretical framework. Dyn. Atmos. Oceans, 13, 171-218, 1989.

Golub, G.H. and van Loan, C.F., 1989. Matrix Computations. Johns Hopkins University Press, 1989.

Haidvogel, Dale B., James C. McWilliams, and Peter R. Gent. : Boundary current separation in a quasigeostrophic, ddy-resolving ocean circulation model. Journal of Physical Oceanography 22.8: 882-902, 1992.

Haidvogel, D. B., Arango, H., Budgell, W. P., Cornuelle, B. D., Curchitser, E., Di Lorenzo, E., ... and Levin, J.: Ocean forecasting in terrain-following coordinates: Formulation and skill assessment of the Regional Ocean Modeling System. Journal of Computational Physics, 227(7), 3595-3624, 2008.

Hansen, J.A. and Smith, L.A.: The role of operational contraints in selecting supplementary observations. J. of the 
Nonlin. Processes Geophys. Discuss., https://doi.org/10.5194/npg-2018-22

Manuscript under review for journal Nonlin. Processes Geophys.

Discussion started: 4 April 2018

(c) Author(s) 2018. CC BY 4.0 License.

Houtekamer, P. L. and Mitchell, H. L.: Ensemble kalman filtering. Quarterly Journal of the Royal Meteorological Society, 131(613), 3269-3289, 2005.

Jiang, S., Jin, F., and Ghil, M.: Multiple equilibria, periodic, and aperiodic solutions in a wind-driven, double-gyre, shallow-water model. Journal of Physical Oceanography 25.5: 764-786. 1995.

5 Kalnay, E.: Atmospheric modeling, data assimilation and predictability. Cambridge University Press, 2003.

Kantz, H. and Schreiber, T.: Nonlinear Time Series Analysis, Cambridge Univ. Press, Cambridge, 2004.

Kelly, G., Thépaut, J. N., Buizza, R., and Cardinali, C.: The value of observations. I: Data denial experiments for the Atlantic and the Pacific. Quarterly Journal of the Royal Meteorological Society, 133(628), 1803-1815, 2007.

Langland, R. H. and Rohaly, G. D.: Adjoint-based targeting of observations for FASTEX cyclones. NAVAL

RESEARCH LAB MONTEREY CA, 1996.

Langland, R. H., Toth, Z., Gelaro, R., Szunyogh, I., Shapiro, M. A., Majumdar, S. J., ... and Bishop, C. H... The North Pacific Experiment (NORPEX-98): targeted observations for improved North American weather forecasts. Bulletin of the American Meteorological Society, 80(7), 1363-1384, 1999.

Langland, R. H.: Issues in targeted observing. Quarterly Journal of the Royal Meteorological Society, 131(613), 3409-

$153425,2005$.

Lorenz, E. N.: A study of the predictability of a 28-variable atmospheric model. Tellus, 17(3), 321-333, 1965.

Lorenz, E.N. and Emanuel, K.A.: Optimal sites for supplementary weather observations: simulation with a small model. J. of the Atmospheric Sciences, Vol. 55, 399-414, 1998.

Majumdar, S. J., Bishop, C. H., Etherton, B. J., and Toth, Z.: Adaptive sampling with the ensemble transform Kalman

filter. Part II: Field program implementation. Monthly Weather Review, 130(5), 1356-1369, 2002.

Molteni, F. and Palmer, T. N.: Predictability and finite-time instability of the northern winter circulation. Quarterly Journal of the Royal Meteorological Society, 119(510), 269-298, 1993.

Moore, A. M., and Farrell, B. F.: Rapid perturbation growth on spatially and temporally varying oceanic flows determined using an adjoint method: Application to the Gulf Stream. Journal of physical oceanography 23.8: 1682-

$25 \quad 1702,1993$.

Moore, A. M. and Mariano, A. J.: The dynamics of error growth and predictability in a model of the Gulf Stream. Part I: Singular vector analysis. Journal of physical oceanography, 29(2), 158-176, 1999.

Moore, A. M., Arango, H. G., Di Lorenzo, E., Cornuelle, B. D., Miller, A. J., and Neilson, D. J. : A comprehensive ocean prediction and analysis system based on the tangent linear and adjoint of a regional ocean model. Ocean

30 Modelling, 7(1-2), 227-258, 2004.

Moore, A. M., Arango, H. G., Broquet, G., Powell, B. S., Weaver, A. T., and Zavala-Garay, J.: The Regional Ocean Modeling System (ROMS) 4-dimensional variational data assimilation systems: Part I-System overview and formulation. Progress in Oceanography, 91(1), 34-49, 2011.

Mureau, R., Molteni, F., and Palmer, T. N.: Ensemble prediction using dynamically conditioned

perturbations. Quarterly Journal of the Royal Meteorological Society, 119(510), 299-323, 1993

OECD: The Ocean Economy in 2030, OECD Publishing, Paris. http://dx.doi.org/10.1787/9789264251724-en, 2016.

Palmer, T. N., Gelaro, R., Barkmeijer, J., and Buizza, R.: Singular vectors, metrics, and adaptive observations. Journal of the Atmospheric Sciences, 55(4), 633-653, 1998.

Palmer, T.N. and Zanna L.: Singular vectors, predictability and ensemble forecasting for weather and climate - J. of

Physics A: Mathematical and Theoretical 46 (2013) 254018(17pp), 2013. 
Nonlin. Processes Geophys. Discuss., https://doi.org/10.5194/npg-2018-22

Manuscript under review for journal Nonlin. Processes Geophys.

Discussion started: 4 April 2018

(c) Author(s) 2018. CC BY 4.0 License.

Pu, Z. X. and Kalnay, E.: Targeting observations with the quasi-inverse linear and adjoint NCEP global models: Performance during FASTEX. Quarterly Journal of the Royal Meteorological Society, 125(561), 3329-3337, 1999.

Rabier, F., Klinker, E., Courtier, P., and Hollingsworth, A.: Sensitivity of forecast errors to initial conditions. Quarterly Journal of the Royal Meteorological Society, 122(529), 121-150, 1996.

5 She, J., Allen, I., Buch, E., Crise, A., Johannessen, J. A., Le Traon, P.-Y., Lips, U., Nolan, G., Pinardi, N., Reißmann, J. H., Siddorn, J., Stanev, E., and Wehde, H.: Developing European operational oceanography for Blue Growth, climate change adaptation and mitigation, and ecosystem-based management, Ocean Sci., 12, 953-976, https://doi.org/10.5194/os-12-953-2016, 2016.

Shen, Jie, Tachim Medjo, T. and Wang, S.: On a wind-driven, double-gyre, quasi-geostrophic ocean model: numerical simulations and structural analysis. Journal of Computational Physics 155.2: 387-409, 1999.

Smith, K.D., Moore, A.M., and Arango, H.G.: Estimates of ocean forecast error covariance derived from Hessian Singular Vectors. Ocean Modelling 89: 104-121, 2015.

Speich, S., Dijkstra, H., and Ghil, M.: Successive bifurcations in a shallow-water model applied to the wind-driven ocean circulation. Nonlinear Processes in Geophysics 2: 241-268, 1995.

15 Szunyogh, I., Toth, Z., Emanuel, K. A., Bishop, C. H., Snyder, C., Morss, R. E., ... and Marchok, T.: Ensemble-based targeting experiments during fastex: the effect of dropsonde data from the lear jet. Quarterly Journal of the Royal Meteorological Society, 125(561), 3189-3217, 1999.

Taylor, K. E.: Summarizing multiple aspects of model performance in a single diagram. Journal of Geophysical Research: Atmospheres 106.D7: 7183-7192, 2001.

20 Toth, Z. and Kalnay E.: Ensemble forecasting at NMC: the generation of perturbations. NMC, Washington DC 20233, 1993.

Trevisan, A. and Uboldi, F.: Assimilation of standard and targeted observations within the unstable subspace of the observation-analysis-forecast cycle system. Journal of the atmospheric sciences, 61(1), 103-113, 2004. 